\title{
Visual-geometric Representation of Theorem Proofs in Nomotex DLS
}

\author{
Yury I. Dimitrienko ${ }^{1}$, Kirill M. Zubarev ${ }^{1 *}$, Elena A. Gubareva ${ }^{1}$, Tatyana L. Ivanova ${ }^{1}$, Raisa \\ $K$. Alesina ${ }^{1}$, and Alexander V. Alesin ${ }^{1}$ \\ ${ }^{1}$ Bauman Moscow State Technical University, 2nd Baumanskaya str., 5/1, 105005, Moscow, Russia
}

\begin{abstract}
The paper examines the features of visual thinking, the authors note the importance of visual examples in modern engineering education. The article describes a methodological approach to presenting the course, based on visual theorem proofs. An example is considered the course "Theory of multivariable function" Visual examples were created at the Department of Computational Mathematics and Mathematical Physics of the Bauman Moscow State Technical University. The proposed methodological approach to the development of the course "Theory of multivariable function" allows you to use the elements of the created course in various variations for disciplines using the concept of functions of many variables, depending on the direction of training (specialty).
\end{abstract}

\section{Introduction}

At the present time, the question is increasingly raised that it is becoming more difficult to win the attention of students every day, they stop attending classes, they perceive classical theorem proofs worse and worse. Because of this, the student is unable to master the subject at the proper level [1-3].

The teacher's increased attention to the individual cognitive characteristics of the cognitive sphere of students contributes to the improvement of the quality of education. Individual methods of studying the material represent the cognitive style of a particular student, which shows how exactly the student perceives this or that material, in what ways he thinks [4]. Taking into account the influence of students' cognitive styles on the process and the result of educational and professional activities significantly increases the quality of student training, and allows them to use their intellectual resources as efficiently as possible [5]. Human consciousness uses two mechanisms of thinking: one of them allows you to work with abstract chains of symbols, with texts, with proofs of theorems (this mechanism of thinking is usually called left-brain, symbolic, algebraic or logical); the second mechanism is based on cognition through visual images and sensory perception (it is called right hemisphere, figurative, geometric or intuitive) [6].

The visualization process is essentially the transformation of the heard text into a visual image that is perceived much easier, and in the case of correct perception and analysis, it may well serve as a support for further mental and practical actions [7-9].

* Corresponding author: zubarevkm@bmstu.ru 
Modern students, as a rule, more often operate not with a chain of logical calculations, but with a set of associative visual images, i.e. their thinking is largely visualized and schematic [11, 12, 13]. Modern students are accustomed to saving time, therefore, they strive for a more concise form of presentation, when the maximum amount of information is conveyed through a minimum of symbols. In fact, we are talking about educational material that requires a minimum of attention, but at the same time carries a large amount of information $[13,14]$.

The visual form of the educational material allows you to clearly demonstrate the causeand-effect and semantic relationships, which is extremely important for the effective development of students' critical thinking. The unusualness and variety of forms of the visualizations used do not dull attention, but, on the contrary, contribute to the fixation of the studied material in the memory [15-17].

In order for students to form the correct visual images, the Nomotex DLS proposed a format for visual proofs of theorems, thus, the teacher himself forms a visual image that is obviously correct, which makes it possible to improve the perception of the material and further work with it $[18,19]$.

\section{Using visual images in the course «Theory of multivariable function»}

\subsection{Features of the course}

The "Theory of multivariable function" is one of the basic disciplines, the understanding of which is necessary for the study of such sciences as physics, optimization methods and others.

The course "Theory of multivariable function" is variably included in various mathematical disciplines taught in the first year of engineering universities. Taking into account the time frame for reading disciplines based on the course "Theory of multivariable function", there is a refusal of proofs, since textual proofs take a lot of time and are not understandable for the student. Avoiding theorem proving in disciplines lowers the level of reading disciplines [20].

When developing the course "Theory of multivariable function", implemented in the DLS Knowledge Base "Nomotex" [17-20], an original methodological approach was proposed for presenting the proofs of theorems of the course, which allows leaving the proofs of theorems in disciplines and at the same time improving the assimilation of concepts, and also increase students' interest in theorem proving [18, 19]. This methodological approach is based on a step-by-step interactive computer visualization of the proof, which is a geometric interpretation of the concepts of the course "Theory of multivariable function" [20].

The course "Theory of multivariable function" is implemented in neural network educational programs for engineers at the Bauman Moscow State Technical University in the framework of the disciplines "Linear algebra and functions of many variables" and "Mathematical analysis". Both disciplines are studied in the first year, in the second semester.

\subsection{Visual proof of the implicit function theorem}

Let us consider this methodical approach using the example of the proof of the implicit function theorem for $\mathrm{n}$ variables. 
The statement of the theorem is a logical construction (traffic light), where the green color represents the initial data: the space where we work and what is given in this space, the yellow field is the assumption about objects. the red box is the statement we want to prove. Thus, the traffic light is a logical structure: Let $\mathrm{A}$, then if $\mathrm{B}$, then there will be $\mathrm{C}$. Each mathematical concept in DLS Nomotex is built according to this logical scheme, which allows the student to build a visual image of the theorem from the very beginning. At first, this format of presentation of mathematical knowledge seems unusual to the student, but literally within a month the student masters it and it becomes easier for him to perceive the material based on this logical structure. The student develops a systematic approach to knowledge, which helps to structure the material being studied. Figure 1 shows the formulation of the implicit function theorem in DLS Nomotex.

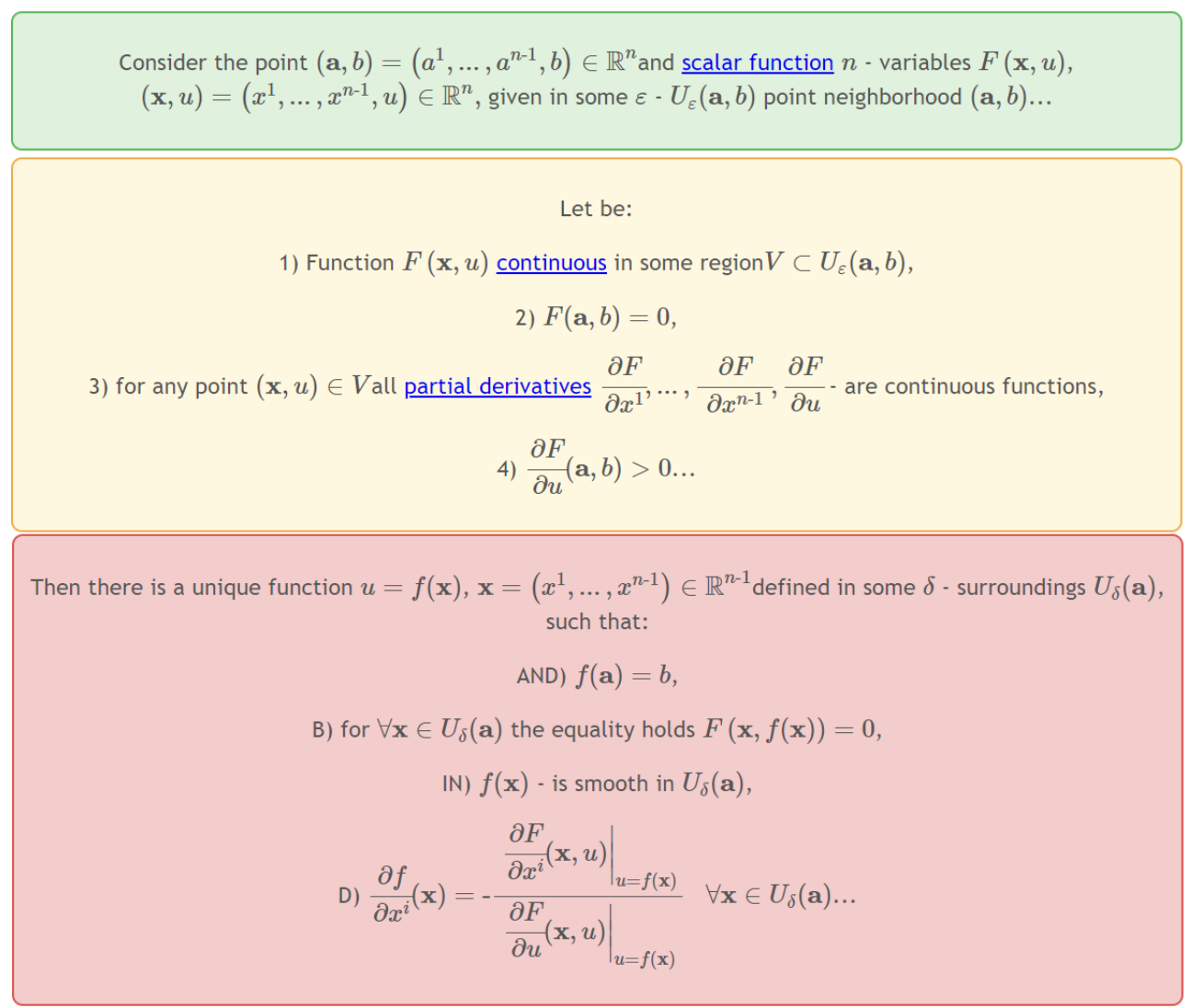

Fig. 1. Formulation of the theorem in the form «traffic light» in the DLS Nomotex.

In the classical course, the proof of this theorem is rather cumbersome and very often students do not understand. To solve this problem, a proof format was proposed based on the visualization of geometric constructions.

A surface is considered, which is a geometric interpretation of a function of two variables and some neighborhood of a point is selected, which is depicted on the surface and on the domain of definition, Figure 2 

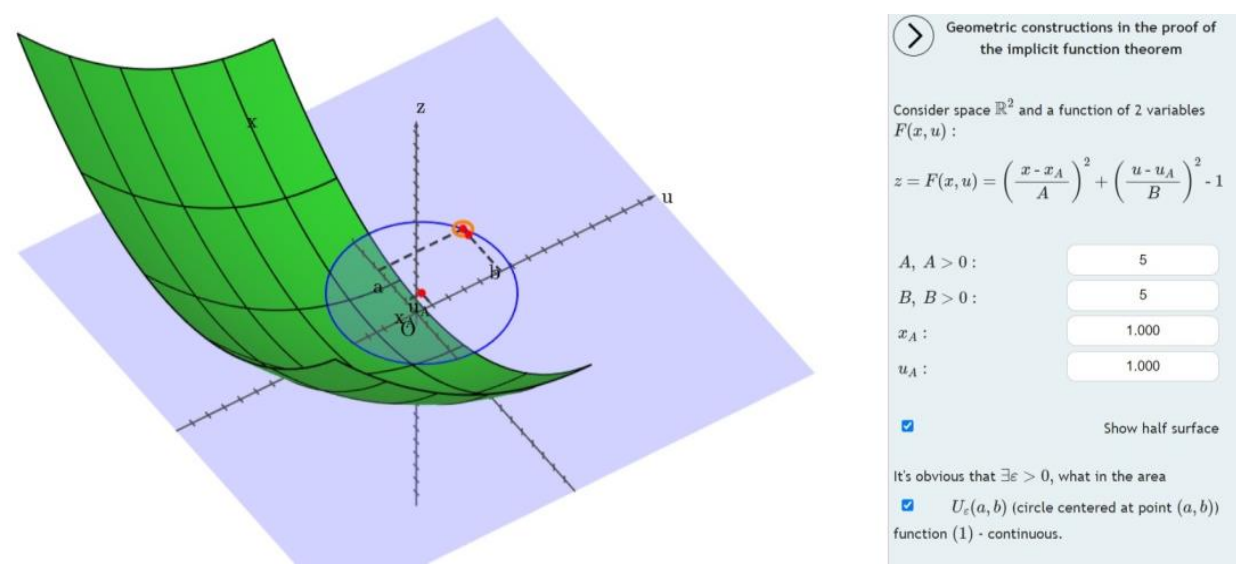

Fig. 2. Visual-geometric proof of the theorem.

Further, in the process of proving the points, visualization is supplemented, the student can track the process of proving the theorem. Figure 3 shows one of the points in the proof of the theorem.
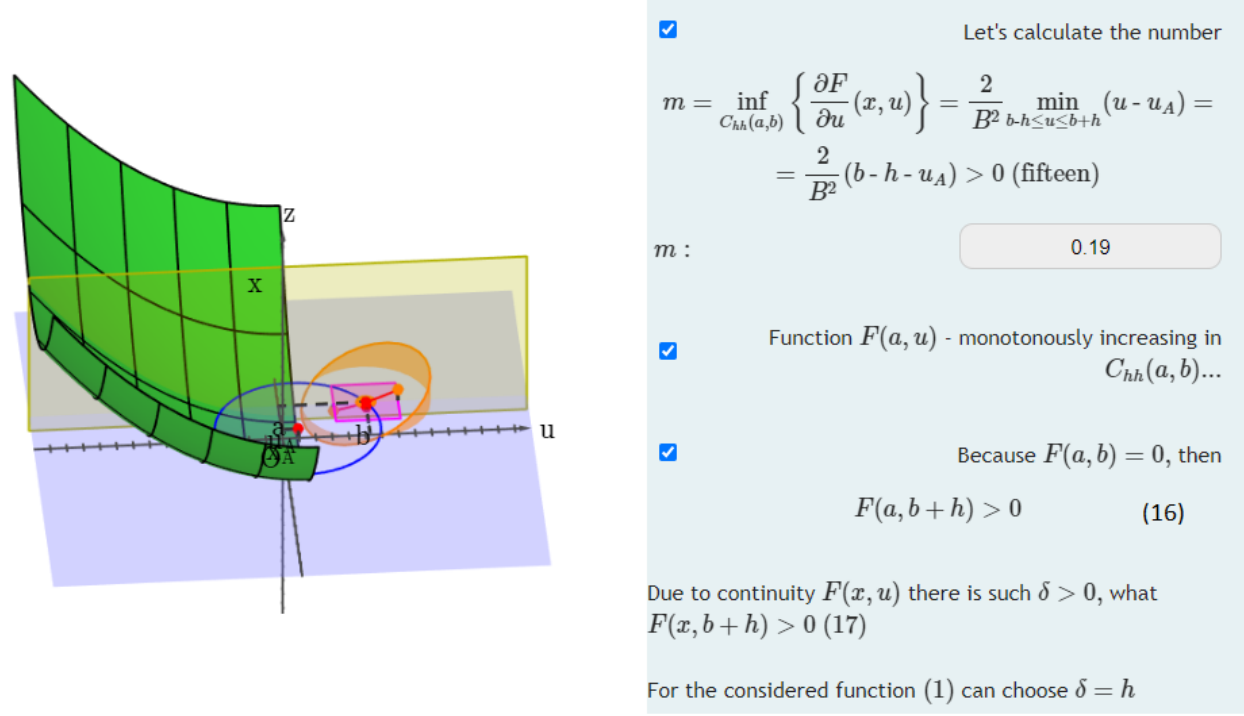

Fig. 3. Visual-geometric proof of the theorem.

Thus, the proof is a chain of geometric constructions, each construction is displayed on the visualization, which allows the student to visualize the proof of the theorem. In the case of successful mastering of the visual proof of the theorem, the student also has the opportunity to analytically prove the theorem.

This approach to proofs was tested within the disciplines "Linear algebra and the "Theory of multivariable function" and "Mathematical analysis". 


\section{Conclusions}

The article describes the problems of modern education, the importance of visual images in the educational process was noted. As an example, a visual geometric proof of the theorem on implicit functions from the course "Theory of multivariable function" was demonstrated. We can say that the new structure of the representation of mathematical knowledge has such a quality as clarity of presentation of the material and makes it easier for students to assimilate knowledge. It also allows us to conclude that, after the students themselves were able to directly work interactively in the DLS Nomotex with mathematical and engineering examples, their perception and presentation of mathematical knowledge improved markedly.

\section{References}

1. Ya.I. Kuzminov, M. Carnoy, Panel discussion, Online Learning: How It Affects the University Structure and Economics, Voprosy obrazovaniya, No. 3, pp. 8-43 (2015)

2. V. Gromyko, V. Kazaryan, N. Vasilyev, A. Simakin, S. Anosov, Artificial intelligence as tutoring partner for human intellect, Advances in intelligent systems and computing, № 658, pp. 238-247 (2018)

3. V. Mayorova, O. Zhdanovich, Innovative collaborative educational programs for space systems engineers, Proceedings of the International Astronautical Congress, IAC (2016)

4. G. Procurat, A. Strukova, A. Vukolov, O. Egorova, Generated graphics and game development software in engineering education: Perspectives and experience of usage, Mechanisms and Machine Science, № 64, pp. 123-130 (2019)

5. N. Serdyukova, V. Serdyukov, S. Neustroev, Testing as a feedback in a smart university and as a component of the identification of smart systems, Smart Innovation, Systems and Technologies, № 144, pp. 527-538 (2019)

6. V. Guznenkov, P. Zhurbenko, The Academic Discipline 'Computer Graphics' for the Open Education System, 2018 4th International Conference on Information Technologies in Engineering Education, Inforino 2018 - Proceedings 8581738 (2018)

7. A. Karpov, Education for knowledge society: Learning and scientific innovation environment, Journal of Social Studies Education Research, № 8(3), pp. 201-214 (2017)

8. K.F. Deborah, Practices for Student Success: From Face-to-Face to At-Scale and Back, Voprosy obrazovaniya, No. 4, pp. 116-138 (2018)

9. V. Potkonjak, M. Gardner, V. Callaghan, P. Mattila, Ch. Guetl, V. Petrović, K. Jovanovic, Virtual Laboratories for Education in Science, Technology, and Engineering: a Review, Computers \& Education, Vol. 95, pp. 309-327 (2016)

10. B. Gan, T. Menkhoff, R. Smith Smith, Enhancing students' learning process through interactive digital media: New opportunities for collaborative learning, Computers in Human Behavior, Vol. 51, Part B, October 2015, pp. 652-663 (2015)

11. L. Braghirolli, J. L. Ribeiro, A. Weise, M. Pizzolato, Benefits of educational games as an introductory activity in industrial engineering education, Computers in Human Behavior, No. 58, pp. 315-324 (2016)

12. M. Janelli, E-Learning in Theory, Practice, and Research, Voprosy obrazovaniya, No. 4, pp. 81-98 (2018) 
13. I. Horváth, Innovative engineering education in the cooperative VR environment, 7th IEEE International Conference on Cognitive Infocommunications (CogInfoCom), pp. 359-364 (2016)

14. C.Y. Chao, Y.T. Chen, K.Y. Chuang, Exploring students' learning attitude and achievement in flipped learning supported computer aided design curriculum: A study in high school engineering education, Computer Applications in Engineering Education, 23(4), pp. 514-526 (2015)

15. J. Gutierrez, C.E. Mora, B. Anorbe-Diaz, A. Gonzalez-Marrero, Virtual Technologies Trends in Education, Eurasia Journal of Mathematics, Science and Technology Education, 13(2), pp. 469-486 (2017)

16. A.P. Markopoulos, A. Fragkou, P.D. Kasidiaris \& J.P. Davim, Gamification in engineering education and professional training, International Journal of Mechanical Engineering Education, 43 (2), pp. 118-131 (2015)

17. Yu. Dimitrienko, E. Gubareva, New technology of mathematical training of engineering personnel, based on a neural network model of knowledge, Innovation in education, № 11, pp. 129-140 (2017)

18. Yu. Dimitrienko, E. Gubareva, K. Zubarev, S. Kudryavtseva, Methodological support of the continuing education of teachers on the development of online courses at bmstu, Science diary, № 11 (2018)

19. Yu. Dimitrienko, E. Gubareva, Hierarchical neural network model for mathematical knowledge and software NOMOTEX for mathematical training of engineers, IOP Journal of Physics: Conference Series, volume 1141012010 doi:10.1088/17426596/1141/1/012010 (2018)

20. Yu. Dimitrienko, E. Gubareva, T. Oblakova, Methodology for assessing knowledge on the course "Mathematical Analysis" in the digital environment NOMOTEX, Innovative development, № 9, pp. 8-11 (2018) 